This is a non-peer-reviewed preprint

\title{
How open science is fighting against private, proprietary publishing platforms
}

Jonathan P. Tennant

IGDORE, Indonesia.

Jon.tennant.2@gmail.com

ORCID: $\underline{0000-0001-7794-0218}$

Article 27 of the United Nations Universal Declaration on Human Rights states that:

(1) Everyone has the right freely to participate in the cultural life of the community, to enjoy the arts and to share in scientific advancement and its benefits.

(2) Everyone has the right to the protection of the moral and material interests resulting from any scientific, literary or artistic production of which he is the author.

\section{Vive la révolution?}

There is a revolution happening in the world of science. It has been gathering pace for some time, like a coming storm. But now we, as a global community, scientist or not, are right within its eye. The SARSCoV-2 pandemic has demonstrated that virtually all of the major issues in global scholarly publishing and communication, including publishing, collaboration, and evaluation, can be extremely easily overcome at a technical level $(1,2)$. Scientists are heroically demonstrating substantial capacity for applying their research skills and knowledge for solving a specific set of problems $(3,4)$.

This revolution is reframing the role and function of science in society, showing that it is something that affects us all in different ways as part of our daily lives (5); from the air we breathe and the water we drink, to the phones in our hands and the lights in our eyes. Science is there, guiding the rules that we all live our lives by. The SARS-CoV-2 pandemic demonstrates so vividly that the main barriers between, and surrounding, institutionalised and public or citizen science can be circumvented when there is a specific goal in mind.

While much of our world has crumbled around us during this pandemic, with many of our politicians and 'leaders' shown to be bafflingly incompetent, our economic models demonstrated to be corrupt 
This is a non-peer-reviewed preprint

and inefficient, and structural inequities so painfully highlighted across the world, scientific knowledge woke up and all of a sudden became the most valuable resource that we have. The great thing about knowledge is that when I share some with you, I still get to keep that knowledge, but you have it now too. Forgive the analogy, but knowledge replicates itself like a virus in many ways. It only ever grows, and is the most sustainable resource that we have. This pandemic has now demonstrated just how valuable unconstrained access to scientific research is, in parallel to having a public that is wellequipped to use it.

This begs the question though, of what scientists and scientific institutes were doing beforehand, if not sharing and collaborating efficiently and effectively to solve the major challenges society faces? Why is it so 'unprecedented' for scientists to now be publishing, peer reviewing, and collaborating, using readily existing and technically feasible practices? Why does scientific knowledge not operate as a good for the public to use to combat every threat we face? In this article, I will argue that it is the private scholarly publishing sector that has corrupted scientific communication through an unholy trinity of demand for more research outputs, readily available metrics around those outputs to capture 'productivity', and total and deliberate marketplace dysfunction. It is the private publishing sector that stands in direct opposition to the goals of making science work for society.

\section{The state of the article}

Countless pages have been spilled already on the injustice that the private scholarly publishing industry imposes upon humanity $(6,7)$. The word 'pages' here should be emphasised, because the primary method of scholarly communication is still considered to be a 'paper' in a 'journal', with innovation levels currently some embarrassing two decades behind every other industry sector. I kid thee not when I say that the best "innovation" that the supposed 'technology leader' in scholarly publishing has made in the last decade is the hyperlink (8). Machine learning, artificial intelligence, blockchain technology, all of these potential catalysts for innovative re-use and production of scientific knowledge have not even began to penetrate the world of scholarly communication. Our current scientific record is functionally useless, comprising some 125 million PDFs owned by a thousand different publishers with a thousand different copyright and re-use terms. It is as obsolete as a hedge fund manager during a global pandemic.

The subscription business model is based primarily on the exploitation of free labour and financial discrimination (9). The industry, in a nutshell, takes the knowledge rights from the research community in exchange for the possible glory of being published in one of their illustrious journals, and then sells it back to the same community at an unholy mark-up (10). Open Access was supposed 
This is a non-peer-reviewed preprint

to shake the industry up, based around the principle that the public deserved to have access to the research that it was funding $(11,12)$. Somehow along the way, through Open Access and 'transformative agreements', researchers, institutes, and governments are now asked to pay to cover, not the production costs for publishing articles, but the costs associated the revenue that commercial publishers will lose if they cannot charge readers and institutes for subscriptions. The same vendors often gather usage data on these processes, using citation networks primarily, and then sell metrics based on those data back to research institutes so they can evaluate their workers and 'incentivise' them to be more efficient. Because everyone knows that great discoveries are made only when scientists are incentivised to make them.

Whether it is called "open science", "open research" or "open scholarship" doesn't matter too much, unless one has a particular penchant for scholarly pedantry (13). At the most granular level, each is about research processes, practices, and underlying values and principles of rigorous, reliable, and reproducible scholarship that is available without restriction to all. At the higher level, though, openness is about control. Or, rather, the lack of it. The opposite of "open" is not "closed", it is proprietary; both in terms of processes and outputs, meaning for open that no-one or no company can claim ownership to it. And this is what the private sector controls. Scientific knowledge can never properly serve society while we have outsourced sovereignty of it to proprietary systems. Open science can be best viewed at its highest level then as an attempt to regain control of the scholarly and scientific communication system from the private publishing sector, and then grant it its freedom.

Many might be surprised, or angered, to know that the vast majority of scientific research that we have ever produced, globally, remains inaccessible to those who fund it, be they public, private, or philanthropic. I mean, the whole idea of modern capitalism is that your life actually does have an economic value or cost, and scholarly publishers are the shining beacon of successful capitalist enterprises (14). Our entire global scholarship legacy, our knowledge culture, our intellectual property, our greatest scientific ideas about understanding and saving our world, have been donated to private companies. It is a competitive facade that has reduced our global intellectual elite chasing meaningless numbers and brands, or instead being chased out of academia. Not only is this perfectly legal, but exactly what the present system has been designed to do.

\section{A 30-year delayed fuse}

In the realms of software, Free and Open Source standards and technologies have become the de facto norm, and are widely-accepted by the public and private sectors $(15,16)$. Open Source was borne out of the Free Software movement in the 1980s, with both based on an intrinsically collaborative 
This is a non-peer-reviewed preprint

development culture but with varying views on re-use permissions. Now, household names, such as Netflix, WhatsApp and even Mac OS, are based at least in part upon Open Source software. It has become a global success. What researchers are doing now in terms of performing and communicating science during the Coronavirus pandemic is remarkably similar to how Open Source software communities function (17).

However, open science is a relatively younger phenomenon, perhaps with its first origins in the scholarly literature in 2001 (18). Open in its many forms in science really took off and became something to talk about in the early 2000s. There was moderate technological innovation during this time, as previously analogue systems had to adapt to become compatible with the digital age. Major initiatives such as PLOS combined with high-level policies, such as the US National Institute of Health's Open Access policy, and caused great grief to the private publishing sector. There was much celebrating.

Now, almost 2 decades later, around 30\% of all scientific research is Open Access; with the time, effort, and money spent to do so in exhaustive numbers (19). The same private players still dominate this landscape, and the technology remains pretty much the same. Despite the overwhelming academic, economic, and societal case for Open Access (20), it is still proving exceptionally difficult to implement because the scholarly private sector will not 'allow' it to dominate unless they can find a way to subvert it through diversification of their revenue streams; this is exactly how for-profit systems are designed to operate. It is at this point that it is worth reiterating that the reason why the World Wide Web was developed was for scientists being able to share data and knowledge with each other instantly and at near-zero costs $(21,22)$. Yet, somehow, large sectors of scholarly publishing have never been slower and more expensive.

\section{Never underestimate the power of greed}

Early attempts at improving public access to science, while marginally successful and disruptive, have now become stagnant, and fall on the ears of a largely apathetic research sector. Virtually all Open Access goals are being ever pushed back, catalysing supra-national initiatives such as Plan $\mathrm{S}$, heavily resisted by a private industry that claims that it cannot adapt fast enough and needs more time (23). Peer review, the supposed "golden standard" of scholarly research, remains curiously poorly understood both empirically and theoretically (24), with publishers again mostly unwilling to release this vital information for further study (25). Critical data and code needed to verify research results are often hidden or locked away silos, un-usable by the majority of people, and often we waste countless hours trying to reproduce the version of research contained in PDFs rather than reproduce 
This is a non-peer-reviewed preprint

actual research (26). This publishing process is a necessary evil, beset by technological inefficiencies at each step. Mind-numbing article submission portals, a timeless void where researchers can spend days just trying to enter files and author information. And let us not forget those wistful summer days spent reformatting references to suit different schemes as articles get bounced down the journal ranking ladder (27). It is perfectly reasonable to delay publication of research for weeks because you forgot to italicise a journal name in the reference list. You should have checked the formatting guidelines first.

The present scholarly publishing industry is among the most profitable [legal] industry on this planet (10). Just a few publishers dominate this landscape, using ruthless and unethical tactics to create a dysfunctional market that stifles any innovation or disruption $(28,29)$. This is not new knowledge. On average, the amount of revenue gained per-article from subscriptions is around $€ 5,000$ (30), about an order of magnitude more than the actual costs of article production and business management (31). None of this revenue is reinvested back to the primary producers (i.e., authors, funders, institutes, or peer reviewers). The two owners of Holtzbrinck, the company that owns Springer Nature, one of the biggest paywall-based publishers, are together worth some USD $\$ 3.5$ billion. Elsevier turns in an annual net profit of about $€ 1$ billion for its shareholders, about $70 \%$ of which comes from the public purse (29). When you successfully generate $30-40 \%$ net profit margins each year on year based on market dysfunction, free labour exploitation, and stagnation, why change a thing. Especially when institutes and research funders keep paying you billions each year to do so.

The primary products of publishers are scholarly journals, like Nature, Science, the appropriately titled Journal of Pain, published by you-know-who, and of course, the prestigious Concrete Abstracts. Publishing, in this context, actually does not mean to 'make public', as with traditional use of the term, but to make private. Commercial publishers are like shoe manufacturers who claim to be athletes and also tell you that running is impossible unless you wear their shoes. Researchers compete with each other to publish in these journals, because for some reason, researchers are dominantly assessed based on where they publish, rather than what (32). My mother told me when I was three years old "Never judge a book by its cover"; and yet, this is the primary evaluation system for global research. The strange thing is that no-one really seems aware of how this system came into place, yet simultaneously everyone knows it is someone's job to fix but also not their responsibility to do so. It is well-known that the highest ranked journals tend to produce the least reliable science $(33,34)$. Researchers are paid to do good research, but incentivised to do bad research, in the greatest display of cognitive dissonance the world of research has ever known.

\section{We need a cunning plan}


This is a non-peer-reviewed preprint

While there are some within the publishing sector truly fighting for positive change, the largest have become comfortable with their dominant positions. Three events just before the end of the decade highlighted just how bad this situation is getting. In brief:

1. The Netherlands handed control of their national scholarly infrastructure over to Elsevier. Researchers and institutes will become locked into a system where they are simultaneously the labour providers, the products, and the consumer $(7,29)$.

2. The American Association of Publishers, along with hundreds of scholarly societies and publishers, lobbied President Donald Trump to delay public access to science (35), despite overwhelming evidence that such 'embargo periods' are unnecessary (36). The global Open Access community responded to this enormous display of force, with a hashtag, \#OAintheUSA.

3. Springer Nature told a coalition of public research funders, Coalitions $S$, that their proposed policy changes around Plan $\mathrm{S}$ were unacceptable and unfair. This was fought back by in a statement from the coalition.

Just like reducing carbon emissions, every country in the world has something to gain by increasing public access to knowledge. However, if some countries in the world, especially those with such power as the USA, continue to place the priorities of the private sector over that of global society, then our future is at an even greater risk. There is no other industry in the world, where it is conceivable that they are allowed to dictate the pace of economic transformation at the cost of the public purse. What these three things together demonstrate is that the publishing industry is attempting to exercise an enormous amount of power to retain control over scholarly communication systems. So, what to do?

While there are many who are raging against the machine, the machine is still in a position of absolute dominance. And it is doing untold damage to our society. Just one example of this injustice is that critical research on Ebola was 'paywalled', and which earlier access to could have saved the lives of many thousands. Most research on cancer, HIV, Alzheimer's, every global health challenge we face, remains privatised and paywalled (37). Most primary research on climate change, inaccessible. We are seeing the same now with SARS-CoV-2 pandemic, and we are going to keep seeing the same thing over and over. Even now, while the Open Access movement is coming to terms with the scale of the opposition it faces in making this knowledge public, the very systems they built are now at high risk of being completely co-opted by the same actors that created the problems in the first place (38).

A new strategy is needed. The public sector could change this dynamic by creating international agreements on public financing tools that allow research libraries and communities to collaborate on building a publicly-run, non-profit, open scholarly communication infrastructure that appreciates and 
This is a non-peer-reviewed preprint

acknowledges the full diversity of scholarly processes and outputs (39). Such already exists in part in Latin America, with SciELO and Redalyc, and OPERAS for the humanities in Europe. Plan S in Europe and AmeliCA in Latin America are steps towards this goal, but still remain wedded to a journal- and article-based system. These initiatives should be 'incentivised' to make science work for society, and to innovate based on Web-native tools that are in the best interests of creating efficient and sustainable research workflow systems. Recently, UNESCO have promised co-operation on open science in the context of the coronavirus pandemic; but they need to step up their game and apply this commitment to all scholarship for all of society, possibly through the generation of new forms of modern research institutes that have the capacity to tackle these complex problems $(1,3,4)$.

Such a large-scale investment system has the funds already needed for it. These funds are locked up in anachronistic agreements with private scholarly publishers, the legality of which remain highly suspect. The incentive for libraries and funders to join such a co-operation would be that they could save substantial financial resources, while simultaneously investing in a more sustainable future. This future would be one with innovation at its core, and ultimately lead to more jobs and funding from the private sector as science took on a new functional role in society. Such new technologies could be focused around the United Nations Sustainable Development Goals, as part of a large-scale, supranational green investment plan, with democratic values at its core. Defunding monopolies while reinvesting it in sustainable infrastructure strikes the balance of deconstructivism and constructivism; it is pointless trying to create a competing system while at the same time you continue to channel $10 \mathrm{~s}$ of billions of euros into the dysfunctional but dominant system that it competes against. Privatisation is poison to science, and it is time we prioritised people over profits.

\section{References}

1. Fecher B. Embracing complexity: COVID-19 is a case for academic collaboration and co-creation. 2020 Mar 17 [cited 2020 Mar 20]; Available from: https://elephantinthelab.org/embracingcomplexity-covid-19-is-a-case-for-academic-collaboration-and-co-creation/

2. Dunleavy DJ. Coronavirus As Impetus For a Lasting Change in Research Culture [Internet]. SocArXiv; 2020 Mar [cited 2020 Mar 20]. Available from: https://osf.io/2ryt3

3. Fritz S, See L, Carlson T, Haklay M (Muki), Oliver JL, Fraisl D, et al. Citizen science and the United Nations Sustainable Development Goals. Nat Sustain. 2019 Oct;2(10):922-30.

4. Tennant J, Francuzik W, Dunleavy DJ, Fecher B, Gonzalez-Marquez M, Steiner T. Open Scholarship as a mechanism for the United Nations Sustainable Development Goals [Internet]. SocArXiv; 2020 Mar [cited 2020 Mar 26]. Available from: https://osf.io/8yk62 
5. Gibbons M. Science's new social contract with society. Nature. 1999;402(6761supp):C81.

6. Himmelstein DS, Romero AR, Levernier JG, Munro TA, McLaughlin SR, Tzovaras BG, et al. Research: Sci-Hub provides access to nearly all scholarly literature. eLife Sciences. 2018 Feb 9;7:e32822.

7. Tennant JP. Democratising knowledge: A report on the scholarly publisher Elsevier [Internet]. Education International; 2018. Available from: https://bit.ly/2PPjwRK

8. Hersh G. Collaboration is the key to open access and open science [Internet]. Times Higher Education (THE). 2019 [cited 2020 Apr 5]. Available from: https://www.timeshighereducation.com/opinion/collaboration-key-open-access-and-openscience

9. Tennant J. Time to stop the exploitation of free academic labour [Internet]. SocArXiv; 2020 Mar [cited 2020 Apr 5]. Available from: https://osf.io/6quxg

10. Buranyi S. Is the staggeringly profitable business of scientific publishing bad for science? [Internet]. The Guardian. 2017 [cited 2020 Mar 6]. Available from: https://www.theguardian.com/science/2017/jun/27/profitable-business-scientific-publishingbad-for-science

11. Chan L, Cuplinskas D, Eisen M, Friend F, Genova Y, Guédon J-C, et al. Budapest Open Access Initiative [Internet]. 2002 [cited 2018 Jan 14]. Available from: http://www.budapestopenaccessinitiative.org/read

12. Suber P. Open access [Internet]. Cambridge: MIT Press; 2007. Available from: http://mitpress.mit.edu/books/open-access

13. Vicente-Saez R, Martinez-Fuentes C. Open Science now: A systematic literature review for an integrated definition. Journal of Business Research. 2018 Jul 1;88:428-36.

14. Mirowski P. The future(s) of open science. Soc Stud Sci. 2018 Apr 1;48(2):171-203.

15. Bretthauer D. Open Source Software: A History. Published Works [Internet]. 2001 Dec 26; Available from: https://opencommons.uconn.edu/libr_pubs/7

16. Willinsky J. The unacknowledged convergence of open source, open access, and open science. First Monday [Internet]. 2005 Aug 1 [cited 2018 Dec 9];10(8). Available from: https://ojphi.org/ojs/index.php/fm/article/view/1265

17. Tennant J, Crick T. What can scholars learn from Open Source software communities during pandemics [Internet]. SocArXiv; 2020 Apr [cited 2020 Apr 5]. Available from: https://osf.io/5kdbx

18. Şentürk R. Toward an Open Science and Society: Multiplex Relations in Language. Religion and Society Is lam Araştırmaları Dergisi [Internet]. 2001 [cited 2020 Feb 27];5. Available from: http://isamveri.org/pdfdrg/D01712/2001_6/2001_6_SENTURKR.pdf

19. Piwowar H, Priem J, Larivière V, Alperin JP, Matthias L, Norlander B, et al. The state of OA: a large-scale analysis of the prevalence and impact of Open Access articles. PeerJ. 2018 Feb 13;6:e4375. 
This is a non-peer-reviewed preprint

20. Tennant JP, Waldner F, Jacques DC, Masuzzo P, Collister LB, Hartgerink ChrisHJ. The academic, economic and societal impacts of Open Access: an evidence-based review. F1000Research. 2016 Sep 21;5:632.

21. Bachrach S, Berry RS, Blume M, Foerster T von, Fowler A, Ginsparg P, et al. Who Should Own Scientific Papers? Science. 1998 Sep 4;281(5382):1459-60.

22. Ginsparg P. ArXiv at 20. Nature. 2011 Aug 10;476:145-7.

23. Enserink M. European science funders ban grantees from publishing in paywalled journals [Internet]. Science | AAAS. 2018 [cited 2020 Apr 5]. Available from: https://www.sciencemag.org/news/2018/09/european-science-funders-ban-granteespublishing-paywalled-journals

24. Tennant J, Ross-Hellauer T. The limitations to our understanding of peer review. 2019 Aug 29 [cited 2020 Mar 7]; Available from: https://osf.io/preprints/socarxiv/jq623/

25. Squazzoni F, Ahrweiler P, Barros T, Bianchi F, Birukou A, Blom HJJ, et al. Unlock ways to share data on peer review. Nature. 2020 Feb;578(7796):512-4.

26. Munafò MR, Nosek BA, Bishop DVM, Button KS, Chambers CD, Sert NP du, et al. A manifesto for reproducible science. Nature Human Behaviour. 2017 Jan;1(1):0021.

27. LeBlanc AG, Barnes JD, Saunders TJ, Tremblay MS, Chaput J-P. Scientific sinkhole: The pernicious price of formatting. PLOS ONE. 2019 Sep 26;14(9):e0223116.

28. Larivière $V$, Haustein S, Mongeon P. The Oligopoly of Academic Publishers in the Digital Era. PLOS ONE. 2015 Jun 10;10(6):e0127502.

29. Tennant J, Brembs B. RELX referral to EU competition authority [Internet]. Zenodo; 2018 Oct [cited 2018 Dec 12]. Available from: https://zenodo.org/record/1472045\#.XBEeoWjOIPY

30. Schimmer R, Geschuhn KK, Vogler A. Disrupting the subscription journals' business model for the necessary large-scale transformation to open access. 2015 Apr 28 [cited 2019 Feb 2]; Available from: https://pure.mpg.de/pubman/faces/ViewltemOverviewPage.jsp?itemld=item_2148961

31. Grossmann A, Brembs B. Assessing the size of the affordability problem in scholarly publishing [Internet]. PeerJ Inc.; 2019 Jun [cited 2020 Mar 6]. Report No.: e27809v1. Available from: https://peerj.com/preprints/27809

32. McKiernan EC, Schimanski LA, Nieves CM, Matthias L, Niles MT, Alperin JP. Use of the Journal Impact Factor in academic review, promotion, and tenure evaluations [Internet]. PeerJ Inc.; 2019 Apr [cited 2019 Apr 19]. Report No.: e27638v2. Available from: https://peerj.com/preprints/27638

33. Brembs B, Button K, Munafò $M$. Deep impact: unintended consequences of journal rank. Frontiers in human Neuroscience. 2013;7:291.

34. Brembs B. Prestigious Science Journals Struggle to Reach Even Average Reliability. Frontiers in human neuroscience. 2018;12:37.

35. Brainard J, MalakoffDec. 18 D, 2019, Pm 4:15. Science groups, senator warn Trump administration not to change publishing rules [Internet]. Science | AAAS. 2019 [cited $2020 \mathrm{Apr}$ 
This is a non-peer-reviewed preprint

5]. Available from: https://www.sciencemag.org/news/2019/12/science-groups-senator-warntrump-administration-not-change-publishing-rules

36. Tennant JP, Crane H, Crick T, Davila J, Enkhbayar A, Havemann J, et al. Ten Hot Topics around Scholarly Publishing. Publications. 2019 Jun;7(2):34.

37. Smith $E$, Haustein $S$, Mongeon $P$, Shu F, Ridde V, Larivière $V$. Knowledge sharing in global health research - the impact, uptake and cost of open access to scholarly literature. Health Res Policy Syst [Internet]. 2017 Aug 29 [cited 2020 Mar 20];15. Available from: https://www.ncbi.nlm.nih.gov/pmc/articles/PMC5576373/

38. Posada A, Chen G. Inequality in Knowledge Production: The Integration of Academic Infrastructure by Big Publishers. In: Cha L, Mounie P, editors. ELPUB 2018 [Internet]. Toronto, Canada; 2018 [cited 2019 Jan 24]. Available from: https://hal.archives-ouvertes.fr/hal-01816707

39. Tennant J. How can we achieve a fully open future? [Internet]. SocArXiv; 2020 Mar [cited 2020 Apr 5]. Available from: https://osf.io/9kjwp

\section{Funding}

No direct funding was provided for this work.

\section{Competing interests}

I am really not a huge fan of Elsevier. 